\title{
O CAMPO DOS FUNDAMENTOS DA EDUCAÇÃO NAS DIRETRIZES CURRICULARES NACIONAIS DE 2015
}

\author{
THE FIELD OF FUNDAMENTALS OF EDUCATION IN THE 2015 \\ NATIONAL CURRICULUM GUIDELINES
}

\begin{abstract}
Fabiane Laranjo Crizel Mestranda em Educação, Universidade Federal do Rio Grande - FURG Rio Grande, Rio Grande do Sul - Brasil laranjocrizelfabiane@gmail.com

Suzane da Rocha Vieira Gonçalves Doutora em Educação Ambiental, Universidade Federal do Rio Grande - FURG. Rio Grande, Rio Grande do Sul - Brasil suzanevieira@gmail.com

Renata Cristina Lopes Andrade Doutora em Educação, Universidade Estadual Paulista “Júlio de Mesquita Filho” - UNESP/Campus de Marília. Marília, São Paulo - Brasil renatacrlopes@yahoo.com.br
\end{abstract}

\begin{abstract}
Resumo: O presente artigo pretende discutir e compreender conceitos, ideias e argumentos em contextos da formação de professores, almejando oportunizar condições explicativas da realidade dos profissionais da educação junto dos fundamentos filosóficos e sociológicos da educação no âmbito das Diretrizes Curriculares Nacionais (DCNs) de 2015. Realizou-se, assim, uma pesquisa teórica e documental para buscar o sentido, a orientação e a promoção das experiências educacionais e formativas. Seguindo este percurso, foi possível vislumbrar os espaços e a indispensabilidade dos Fundamentos da Educação na formação docente, nos cursos de Licenciaturas, a partir das DCNs para a Formação de Professores/2015. Com isto, evidenciou-se a importância da presença dos fundamentos na formação docente, com o propósito de que o ato educativo aconteça de modo pleno e com a finalidade de se compreender a vida, vivências e sociedades, as interpretar e ter a ciência de que podemos transformá-las, conjuntamente.
\end{abstract}

Palavras-chave: Fundamentos da educação. Diretrizes curriculares nacionais. Formação de professores.

Abstract: This article aims to discuss and understand concepts, ideas and arguments in contexts of teacher education, aiming to provide opportunities for explanatory conditions of the reality of education professionals along the philosophical and sociological foundations of education within the scope of the National Curriculum Guidelines (DCNs) of 2015. So, a theoretical and documentary research was carried out to seek the meaning, orientation and promotion of educational and formative experiences. Following this path, it was possible to glimpse the spaces and the indispensability of the Fundamentals of Education in teacher education, in undergraduate courses, from the DCNs for Teacher Training/2015. Thus, it was evidenced the importance of the presence of fundamentals in teacher education, with the purpose that the educational act happens in a full way and with the purpose of understanding life, experiences and societies, interpreting them and taking consciousness that we can transform them together.

Keywords: Fundamentals of education. National curriculum guidelines. Teacher training.

Para citar - ABNT NBR 6023:2018

CRIZEL, Fabiane Laranjo; GONÇALVES, Suzane da Rocha Vieira; ANDRADE, Renata Cristina Lopes. O campo dos fundamentos da educação nas diretrizes curriculares nacionais de 2015. Cadernos de Pós-graduação, São Paulo, v. 19, n. 2, p. 70-82, jul./dez. 2020. Disponível em: https://doi.org/10.5585/cpg.v19n2.18489. 


\section{Introdução}

O presente artigo intenciona, tendo por base as Diretrizes Curriculares Nacionais (DCNs) para a formação de professores/2015, refletir e debater sobre a importante questão da presença dos fundamentos da educação nos cursos de licenciaturas.

Ainda, este texto apresenta-se como uma análise teórica e documental, na qual almejamos reestabelecer conceitos e ideias, investigar problemas e argumentos, buscando proporcionar discussões e condições explicativas da realidade formativa dos profissionais da educação junto dos fundamentos filosóficos e sociológicos da educação no âmbito das DCNs/2015, no sentido de compreensão, orientação e promoção das experiências educacionais e formativas.

Diante das problemáticas a serem enfrentadas pela educação brasileira na atualidade, um fator em sua base merece bastante atenção: a formação inicial docente.

Deste modo, com o intuito de problematizarmos sobre essa formação, utilizamos as Diretrizes Curriculares Nacionais (DCNs) para a Formação de Professores de 2015 para dar rumo a considerações a respeito da urgência dos Fundamentos da Educação nos cursos de Licenciaturas.

Logo, é possível questionarmos sobre quais as implicações, para a formação docente, dos Fundamentos Filosóficos e Sociológicos nos currículos das licenciaturas e quais são as consequências da ausência dos Fundamentos na formação dos professores.

É mister termos consciência de há vários projetos de sociedade, educação, cultura e formação de professores para a educação básica em constantes processos de embate no ramo das políticas que se referem ao ato educativo. Isso se dá pela questão de haver interesse do governo em gerenciar a condução do sistema educacional, em gerir a identidade profissional do professor, definindo que categoria é essa (LAWN, 2001).

Portanto, se o professor conduz seu aluno para a vida, segundo a formação que tem, é urgente estarmos situados em relação a que tipo de formação docente e, por consequência, de sujeito (discente) estamos sendo direcionados.

Assim, notarmos a que interesses a questão educativa está sujeitada e sabermos qual atitude deve ser tomada é essencial para uma educação de caráter universal, democrático, laico, crítico, plural, humano e de qualidade.

É nesse viés, ademais, que afirmamos a urgência dos Fundamentos da Educação - filosóficos e sociológicos - estarem presentes nos currículos da formação de professores, pois possibilitam o perceber, o entender, o indagar e o pensar novamente a realidade posta, visando sua transformação. 
Para tanto, levando em consideração as políticas educacionais brasileiras, em sua nova fase, inaugurada segundo Dourado (2015), com a questão da aprovação do Plano Nacional de Educação/PNE pelo Congresso Nacional e a sanção Presidencial que resultaram na Lei no 13.005/2014, em conjunto com metas e estratégias que proporcionaram os alicerces para que se possa efetivar uma política nacional de formação dos profissionais da educação, as quais foram levadas em conta nas diretrizes curriculares nacionais para a formação dos profissionais do magistério, podemos questionar sobre qual é o espaço e a relevância dos fundamentos da educação.

Tais reflexões podem ser justificadas quando percebemos a urgência das políticas educacionais e a importância de os fundamentos filosóficos e sociológicos da educação estarem presentes nas licenciaturas, em seus currículos, com o intuito de que a formação inicial do professor seja plena. Vejamos, então, as exigências entre os fundamentos da educação, a formação de professores e as DCNs/2015.

\section{Compreendendo as diretrizes curriculares nacionais de 2015}

No momento posterior ao processo de aprovação do Plano Nacional de Educação, ocorreu um movimento de intensificação na aprovação de alterações legais e que trouxeram transformações vultuosas na questão da formação de professores em nosso país.

Como elucidado, entre as propostas estavam as Diretrizes Curriculares Nacionais para a formação inicial em nível superior (cursos de licenciatura, cursos de formação pedagógica para graduados e cursos de segunda licenciatura) e para a formação continuada, aprovadas em 2015 (Resolução no 2, de julho de 2015), as quais propuseram novas direções às licenciaturas e determinavam até junho de 2017, como prazo final para esta adaptação curricular dos cursos. No entanto, tal prazo foi postergado até dezembro de 2019.

Evidenciamos que as DCNs de 2015 eram normas obrigatórias para a formação inicial e continuada dos docentes brasileiros em nível superior e que foram grandemente debatidas, arquitetadas e implantadas pelo CNE.

Bazzo e Scheibe (2019), nos ajudam a entender o pano de fundo dessa movimentação ao exporem que a Resolução CNE/CP n 02/2015 - a qual foi discutida em exaustão com a comunidade educacional, entidades acadêmicas e associações (ANFOPE, ANPED, ANPAE, CNTE, dentre outras), assim como com os pesquisadores e educadores do setor das políticas públicas de formação docente - foi mencionada como "uma importante e bem elaborada síntese das lutas históricas da área em torno ao tema". 
Neste contexto, para Dourado (2015), era fato que as DCNs de 2015 estabeleciam os princípios da formação inicial e continuada de profissionais do magistério da educação básica e apontavam para uma maior organicidade nos projetos formativos e ampla articulação entre as instituições de educação superior e de educação básica. O mais precioso, entretanto, é esclarecermos que as DCNs direcionam o planejamento curricular das escolas e dos sistemas de ensino.

Segundo declaram Carvalho e Gonçalves (2018): "É notório que o documento atual procurou contemplar demandas anunciadas já a bastante tempo por pesquisadores, entidades e professores para a qualificação da formação dos profissionais do Magistério". Portanto, as DCNs de 2015 atendiam demandas antigas dos docentes.

Dourado (2015) ao tratar das DCNs de 2015, conclui que:

As novas DCNs definem a seguinte estrutura e currículo dos cursos de formação inicial. Os cursos de formação deverão garantir nos currículos conteúdos específicos da respectiva área de conhecimento ou interdisciplinares, seus fundamentos e metodologias, bem como conteúdos relacionados aos fundamentos da educação, formação na área de políticas públicas e gestão da educação, seus fundamentos e metodologias [...]. (DOURADO, 2015, p. 309).

Se faz necessário evidenciarmos que as DCNs não são uma proposta de um currículo mínimo. E, ainda, que não é mister que os conteúdos estabelecidos por elas estejam explícitos, no próprio nome de alguma disciplina, já que podem estar presentes, mesmo que de modo transversal, no interior de outras disciplinas do currículo.

Dessa forma, as universidades poderiam gerenciar como estes conteúdos seriam considerados nas suas licenciaturas, conforme suas demandas e especificidades. Na explanação de Mallat (2017, p. 2):

Especialmente em 2015, com a apresentação das Diretrizes Curriculares Nacionais para a formação inicial e continuada em nível superior para a educação básica, temos a oportunidade de discutir e repensar a formação docente numa perspectiva formativa e agora também política. Sabemos que a formação de professores deve estar alinhada às novas demandas e a necessidade de aperfeiçoamento constante, uma vez que a educação não se dá somente no interior da escola, pelo contrário, é fruto das relações sociais, interpessoais, de comunicação entre grupos e do contexto histórico e social em que estamos inseridos.

Por certo, é possível declararmos que as DCNs trazem um pensar novo da formação docente, em especial, a formação inicial de professores, a qual não é solitária, mas está associada aos aspectos sociais locais, nacionais e, ainda, globais. As DCNs de 2015 uniam as demandas, novamente, da educação básica com a formação no ensino superior, o que julgamos, juntamente com as considerações de Hobold, de extrema necessidade. 
As pesquisas sobre os cursos de licenciatura têm sido constantes nos últimos anos. As reformas educativas dos anos de 1990 trouxeram novas exigências e direcionamentos aos cursos de formação inicial de professores e, ao mesmo tempo, puseram em evidência o campo da formação docente que se torna mais presente nos debates sobre as políticas públicas, bem como nos eventos da área de educação. (HOBOLD, 2008, p. 2).

É essencial expormos que o interesse pela temática da investigação das licenciaturas é antigo, especialmente após as transformações que surgiram na seara da educação depois de 1990. Mesmo tendo sido sinalizadas como um grande avanço para a formação docente, as DCNs de 2015 foram interpeladas pelo Governo Temer (2016) sob a alegação de que seriam demasiadamente teóricas e, portanto, haveria a suposta necessidade de que fossem revistas, no quesito da prática.

Deste modo, após 2016, notamos o regresso de uma fala pragmática, voltada para a formação docente e apregoa-se, como já referido, a postergação do tempo para implementação dessas diretrizes, tal fato gera a desmobilização das universidades nessa direção.

A fim de melhor contextualizarmos e para que haja bom entendimento a respeito das DCNs, é importante evidenciarmos que:

\begin{abstract}
O cenário político brasileiro teve uma mudança drástica, após maio de 2016, quando o país vivenciou um golpe civil, jurídico e midiático que levou ao afastamento da presidenta Dilma Rousseff. No mês de agosto do mesmo ano, foi aprovado pelo senado o impeachment de Dilma Rousseff. Desde então, temos presenciado uma série de redirecionamentos nas políticas públicas brasileiras, em especial as da educação, que representam um grande retrocesso. No campo educacional o novo Ministério da Educação tem adotado uma política voltada as instituições privadas e ao interesse de empresários, assumindo uma perspectiva neoliberal, tem pautado suas ações em uma visão de educação meritocrática e produtivista. Diante desse novo contexto, as atuais diretrizes para a formação de professores passam a estar em risco, pois há uma grande pressão do empresariado que compactuou com o golpe para que elas sejam revogadas ou passem por uma revisão. (CARVALHO; GONÇALVES, 2017, p. 135-136).
\end{abstract}

Neste ponto, mencionamos um fator que nos trouxe bastante estranheza: antes de ocorrer o impeachment de Dilma Rousseff, o Ministério da Educação/MEC conduziu o reencaminhamento dos que compunham o Conselho Nacional de Educação, todavia o presidente interino Michel Temer revogou a nomeação dos doze conselheiros, sendo que um deles era o professor Luiz Fernandes Dourado, o relator das diretrizes.

Carvalho e Gonçalves (2017) evidenciam que o ato do governo Temer, na época, acabou por não contemplar a continuidade do trabalho de certa parte dos conselheiros que estavam sendo reconduzidos ao CNE e optou por realizar uma indicação sem dialogar com as entidades e instituições.

Por esses motivos, entre outros, as DCNs de 2015 poderiam estar em risco, pois em algumas universidades a implementação foi desacelerada, já que muitos gestores esperavam modificações no texto das diretrizes. 
O centro da discussão era a carga-horária, porque se por um lado as instituições de viés privado ansiavam por cursos de menor carga horária para acelerar a formação, por outro lado a carga horária mais extensa exigia das instituições públicas o ato de contratar um número maior de professores e o MEC não estava dando aval a este ponto específico.

Logo, com a situação do impeachment - o qual concebemos como sendo um "Golpe civil, jurídico e midiático, no qual a presidenta Dilma Rousseff é afastada e assume interinamente a Presidência do País o vice-presidente Michel Temer”. (GONÇALVES, 2017, p. 134) - se deu a reformulação do Conselho Nacional de Educação (CNE) e, também, a inserção de outros integrantes no Ministério da Educação (MEC), as quais passaram a compor o MEC após 1990.

Levando-se em consideração essa premissa, a caminhada esperada para a formação docente, com as diretrizes de 2015, não se consolida, pois segundo o ambiente vivido desde 2016, a implantação das DCNs/2015,

[...] começou a sofrer injustificável demora entre as instituições formadoras. No processo de troca de orientação política em todas as esferas do poder, no pós-Golpe, a referida legislação, elaborada, discutida e aprovada pelo Conselho Nacional de Educação, cujos membros mais progressistas foram, nesse novo momento, substituídos, teve sua implantação inicialmente atravessada por tentativas oficiais de procrastinação [...] Percebendo o perigo de que a implantação da resolução sofresse algum processo de continuidade, dadas as novas orientações que passaram a hegemonizar as decisões do CNE/MEC, a comunidade educacional, por meio de suas entidades representativas (Anfope, Anped, Anpae, CNTE, entre as mais significativas), reforçou seu apoio à Resolução $\mathrm{CNE} / \mathrm{CP} \mathrm{n}^{\circ}$ 02/2015 e passou a exigir sua imediata entrada em vigência. Mesmo assim, esse processo foi sofrendo novas postergações por meio do adiamento de datas em sucessivas ações do CNE. (BAZZO; SCHEIBE, 2019, p. 671).

Deste modo, é possível afirmarmos que, para o CNE/MEC, o legítimo objetivo das distintas postergações era o de que a Base Nacional Comum Curricular da Educação Básica/BNCC (2017) viesse a ser o norte para se compreender as novas políticas educacionais (AGUIAR; DOURADO, 2019).

Assim, é notório que a educação, as DCNs, o neoliberalismo, as políticas públicas e o currículo estão conectados, sendo mister captarmos o instante em que os interesses mercadológicos começam a ter primazia sobre os educacionais, com o intuito de minimizar esta questão. Cabe aos docentes, especialistas da educação, entidades representativas dos professores, alunos, enfim, a todos os cidadãos que anseiam por equidade e justiça social, a responsabilidade por esta atitude. Portanto, é preciso que estejamos cientes e ativos, a fim de podermos ir de encontro a esta barbárie (ADORNO, 1995).

A seguir, ancoradas nas DCNs/2015, dedicamo-nos a refletir sobre os fundamentos na formação do docente, já que, segundo o nosso entendimento, os fundamentos da educação necessitam estar presentes para que a formação inicial de professores e professoras seja integral. 


\section{Fundamentos filosóficos e sociológicos da educação}

Depois de explanarmos sobre o contexto das diretrizes para a formação inicial de professores de 2015, iremos tratar agora sobre elementos referentes à importância e ao lugar que ocupam os fundamentos da educação na formação docente.

Tendo em consideração, em nosso prisma, que a Sociologia e a Filosofia estão fortemente imbricadas, ponderaremos, neste instante, sobre a necessidade destes fundamentos da educação estarem presentes no currículo das licenciaturas, demonstrando aspectos que são essenciais para se pensar e se efetivar o ato educativo.

Como seres humanos, existe uma vontade de captarmos o que somos com o intuito de encontramos um norte pra nosso desenvolvimento, logo isso é bastante precioso, pois caso não saibamos definir o que somos e tampouco para onde vamos, haverá uma imensa probabilidade de estagnação e de nos tornarmos coadjuvantes de nossa própria vida e história. Deste modo, seremos reféns do que outras pessoas escolhem, o que podemos denominar de heteronomia (FREIRE, 2000) ou como concebemos na linguagem popular: "massa de manobra".

Nesse mesmo viés, é possível inferirmos que de forma triste e mesmo sem intencionalidade podemos vir a contribuir para nossa autodestruição. Assim, entendemos que estudarmos e compreendermos a tarefa crítica da sociologia e da filosofia nos auxiliará a evoluir na formação inicial docente.

Conforme Chauí (2010, p. 21):

[...] a primeira resposta para a pergunta 'O que é filosofia?’ poderia ser: a decisão de não aceitar como naturais, óbvias e evidentes as coisas, as ideias, os fatos, as situações, os valores, os comportamentos de nossa existência cotidiana; jamais aceitá-los sem antes havê-los investigado e compreendido.

Alicerçados na afirmação acima, é que declaramos o nosso conceito de Filosofia. Logo, percebemos que aquilo que se refere ao ser humano não pode ser concebido como "obra do acaso".

Portanto, de fato, existe intencionalidade, motivos, os quais necessitam ser entendidos e debatidos. Desse modo, não há neutralidade, tampouco obviedade ou, ainda, imparcialidade no que tange às relações humanas.

É possível nos valer da constatação de Aranha (1989, p. 41):

A visão da filosofia é uma visão de conjunto, ou seja, o problema tratado nunca é examinado de modo parcial, mas sempre sob a perspectiva de conjunto, relacionando cada aspecto com os demais do contexto em que está inserido. Portanto, a realidade que fora fragmentada pelo saber especializado de cada ciência particular é resgatada na sua integralidade pela filosofia, a única capaz de fazer uma reflexão crítica e global sobre o saber e a prática do homem. 
Aí está a relevância da filosofia, devido a sua imparcialidade, seu modo de examinar os acontecimentos e ações de forma não-isolada, analisando o problema e dando possibilidades para o resgate da realidade, do pensar e refletir cauteloso que alcança a totalidade.

Nesse sentido, podemos declarar que a filosofia continua sendo governada pelos questionamentos a respeito do ser humano - conhecimento, amor, cultura, felicidade, justiça, amizade, linguagem, ciência, razão, paixão, liberdade, religião, política, arte, poder (...).

Além disso, se a filosofia foi e é guiada pelas indagações a respeito do ser humano, a educação, que abarca o próprio ser humano em seus fundamentos, não estaria imune ao olhar filosófico, ou seja, se a filosofia é uma reflexão rigorosa, partindo de questões colocadas pela própria natureza, condição e existência do ser bumano, é indispensável que dentre esses questionamentos, investigações e reflexões se façam presentes as que se direcionam à Educação.

Então, é o que ocorre, na filosofia: o zelo com a Educação, quer seja direta ou indiretamente, continua presente, pelos seus processos, sentidos, objetivos, fins e finalidades, valores, concepções - de educação, de humanidade ou de ser humano -, currículos, técnicas, métodos, enfim, preocupações de ordem antropológica, axiológica e epistemológica.

Já a sociologia, ao direcionar sua visão para a educação, é um campo disciplinar que visa estudar os acontecimentos sociais no tocante ao ensino e à aprendizagem. Exemplificando, são analisados por ela os processos institucionais e organizacionais, nos quais a sociedade se respalda para promover a educação aos indivíduos, bem como as relações sociais que marcam o desenvolver-se dos integrantes.

Conforme Schwartzman (1997), na sociologia de Émile Durkheim, a educação era entendida não apenas como necessidade instrumental das sociedades modernas, mas como o único cimento que poderia efetivamente mantê-la solidária e unida.

Segundo Weber (1974), para Bourdieu, um campo social se caracteriza como sendo um lócus de disputa entre os distintos agentes que acabam por compô-lo. Tal colocação soma-se ao que temos constatado, pois qualquer atividade proveniente do homem é perpassada por lutas.

Do viés crítico, as questões de política econômica - intrinsecamente atreladas às condições de sustento material dos indivíduos e às desigualdades, divisões e conflitos que ocorrem na sociedade - acabam por afetar direta ou indiretamente, também, os demais aspectos da sociedade, incluindo os educacionais. Deste modo, é no local escolar e nos processos de aprendizagem, de modo geral, que se tecem ideologias ou ideias que correspondam aos variados modos de produção. $\mathrm{Na}$ atual situação, a escola demonstra estar preparada para servir as demandas do capitalismo.

Kuenzer (1999) declara que: 
[...] não existe um modelo de formação de professores a priori, mas modelos que se diferenciam, dadas as concepções de educação e de sociedade que correspondem às demandas de formação dos intelectuais (dirigentes e trabalhadores) em cada etapa de desenvolvimento das forças produtivas, em que se confrontam finalidades e interesses que são contraditórios. (KUENZER, 1999, p.166).

Como explanado, o que acontece no mundo do trabalho e nas relações sociais ecoa na área educacional, sendo elas, portanto, situações indissociáveis. Aos docentes, cabe a tarefa de compreender o momento atual e saber a quem ele está atendendo. Assim, a partir deste ponto, terão a oportunidade de indagar a respeito daquilo que lhes parecer contraditório e agir segundo o que thes é permitido, todavia buscando construir, de forma conjunta, modos possíveis de se intervir, os quais possuam, verdadeiramente, uma vertente democrática, tal como consta na constituição brasileira.

Kuenzer (1999) ao tratar das políticas de formação docente e de suas identidades, acaba por concluir que elas reverberam nas questões sociais e, logo, afirma:

[...] as demandas de formação de professores respondem a configurações que se originam nas mudanças ocorridas no mundo do trabalho e nas relações sociais, e a configurações oriundas das diferentes posições que são assumidas em relação aos projetos apresentados pelo grupo que ocupa o poder a partir de determinada correlação de forças. (KUENZER, 1999, p. 166).

Concordando com a citação acima e, simultaneamente, indo além neste pensamento, trazemos outro excerto de Kuenzer (1999, p. 173 -174):

Contudo, é inegável o compromisso da escola pública, e, portanto, de seus professores, com o enfrentamento das desigualdades, pela democratização dos conhecimentos que minimamente permitirão os alunos participar, da melhor forma possível, da vida social e produtiva.

Nesse prisma, constatamos que os fundamentos baseados em análises sociológicas, e, especialmente, a sociologia da educação, são de inegável valia, na formação inicial da totalidade dos professores, segundo estabelecido nas diretrizes de 2015.

Vejamos, se ansiamos por formar e desenvolver o ser humano, através da educação, esse é um tipo conhecimento (os fundamentos), também, indispensável, por seu valor intrínseco e/ou por seu valor prático enquanto práxis, portanto, necessitamos proporcionar as condições para que o pensamento e a teoria se realizem como práxis (SEVERINO, 2001), em um diálogo íntimo entre a teoria e a prática, para que as realidades - educativas, formativas, profissionais - sejam modificadas e transformadas. 
Assim, teríamos a teoria e o pensamento agindo sobre o futuro docente, mas também o futuro educador atuando sobre a teoria, ou seja, a reflexão e as experiências reais, afastando visões parciais ou a inexistência desse olhar.

Em relação aos fundamentos da educação, é justamente a presença de tais elementos que encontramos assegurados nas DCNs/2015, ao trazer e exigir a união entre a teoria e a prática, enquanto um princípio que norteia a base comum nacional para a formação inicial e continuada de professoras e professores no Brasil (DCNs, 2015, p. 2), sustentando uma formação ampla e cidadã.

No sentido dessa (e para essa) formação plena, de integração e interdisciplinaridade curricular, de construção dos conhecimentos, de dinâmicas pedagógicas, de condições para o exercício da reflexão e do pensamento crítico, de problematização e interpretações das realidades, de criatividade, emancipação e autonomia, as DCNs/2015 estabeleciam em seu artigo quinto:

Art. $5^{\circ}$ A formação de profissionais do magistério deve assegurar a base comum nacional, pautada pela concepção de educação como processo emancipatório e permanente, bem como pelo reconhecimento da especificidade do trabalho docente, que conduz à práxis como expressão da articulação entre teoria e prática e à exigência de que se leve em conta a realidade dos ambientes das instituições educativas da educação básica e da profissão. (DCNs, 2015, p. 6).

Assim, para garantir a efetivação da formação crítica, emancipada e autônoma, ao cuidar da estrutura e currículo dos cursos de formação inicial de professores para a educação básica em nível superior, em cursos de licenciatura, com o olhar atento aos fundamentos da educação, à união entre teoria, pensamento e prática, as DCNs, definem:

$\int 3^{\circ}$ Deverá ser garantida, ao longo do processo, efetiva e concomitante relação entre teoria e prática, ambas fornecendo elementos básicos para o desenvolvimento dos conhecimentos e habilidades necessários à docência. (DCNs, 2015, p. 11).

Por fim, considerando as nossas análises e reflexões, afirmamos que com a ausência dos fundamentos educacionais, por certo, teremos devastadores prejuízos na formação docente, como: a não possibilidade de reflexão a respeito de qual ser humano desejamos formar e, ainda, do entendimento do papel do professor, da função da educação, bem como da formação e desenvolvimento dos discentes - um desenvolvimento formativo e realizador - partindo de conceitos, de ideias e de pressupostos educacionais, visando chegarmos a uma formação sólida e plena.

\section{Considerações finais}

Aos termos a compreensão da vultuosidade das Políticas Públicas Educacionais para a eficácia da educação, quando percebemos a relação que há entre os Fundamentos e a Educação para 
a formatação das adjacências do processo educativo, entendemos a educação como um acontecimento histórico e social.

É, pois com os Fundamentos da Educação e, especialmente, através da filosofia que aprendemos a urgência de interpelarmos, desconfiarmos e aferirmos o porquê de determinadas circunstâncias serem como são. É um direito e uma opção o não crermos nas dadas realidades, antes de efetuarmos uma diligente averiguação sobre os fatos, para assim podermos configurar o nosso pensar perante a uma firmada realidade.

Já com a sociologia, reconhecemos que pensarmos e repensarmos a sociedade através da educação ou ao contrário refletirmos sobre a educação através da sociedade, do instante que ela vive, é indubitavelmente uma atitude preciosa e que não podemos dispensar na formação de professores. Até porque, como corrobora Kuenzer (1999), a formação docente em si está sujeita a formatação social do contexto vivenciado, ou seja, ela será a regente. A nós, resta a atribuição de percebermos que força a está coordenando, com o intuito de encontrarmos condições para executarmos efetivamente o processo democrático.

A afirmação de Bazzo e Scheibe (2019) sobre o fato de que ao revisitarmos os doze "considerandos" que embasam teórica e politicamente à Resolução CNE/CP n 2/2015, temos a certeza de que estavam ali sintetizados os fundamentos da educação no Brasil tecidos, no mínimo, durante trinta anos pelos professores progressistas, vem em muito a enriquecer o já exposto até o momento.

Entretanto, é notório que os contínuos e sequenciais adiamentos das DCNs 2015, até desaguarem na sua revogação com a Resolução CNE/CP N 2/2019, como previsto pelas entidades representativas dos educadores, tiveram uma motivação: acatar as orientações dos desastrosos e conservadores governos golpistas, os quais lograram um imenso retrocesso ao fingirem não saber do esforço conjunto de educadores extremamente comprometidos com a formação docente, nas últimas décadas.

Sabidamente, as DCNs de 2015 acabaram por ser revogadas e deram lugar à apressada nova versão de Diretrizes, aprovada pela Resolução CNE/CP n ², de 20 de dezembro de 2019 e homologada pela Portaria n ${ }^{\circ}$ 2.167, de 19/12/2019, assinada pelo Ministro de Estado da Educação substituto -, Antônio Paulo Vogel de Medeiros. Tal ato, foi considerado pelos especialistas em políticas educacionais e pelas entidades de educação que representam os docentes como uma regressão, já que a formação de professores perdeu seu teor nas DCNs de 2019.

Ademais, os fundamentos desta legislação incidem em preceitos que não condizem com os elencados nas Diretrizes Curriculares Nacionais para a Formação Inicial e Continuada em Nível Superior de Profissionais do Magistério para a Educação Básica, conforme a Resolução CNE/CP 
$n^{\circ}$ 02/2015, essencialmente no que tange à articulação entre formação e valorização dos profissionais da educação, onde dava-se evidência, de forma pioneira, à demanda da formação continuada desses profissionais. Este último elemento, inclusive, postergado na nova legislação.

Restam, ainda, as ponderações a respeito de entendermos que na atmosfera educativa deve existir somente vencedores e que o ato educativo de qualidade não pode ser negociável. É nesse sentido, também, que insistimos na presença imprescindível dos fundamentos educacionais no currículo da formação inicial docente para que ela seja de qualidade eficaz, plural e crítica.

Deste modo, finalizamos as presentes reflexões com a consciência de que é mister a presença dos fundamentos na formação docente, particularmente tratados aqui: a formação filosófica e sociológica, com o propósito de que o ato educativo aconteça de modo pleno, com a finalidade de se compreender a vida, vivências e sociedades, as interpretar e ter a ciência de que podemos transformá-las, conjuntamente. Indicamos que esse diálogo necessita ser permanentemente efetivado entre todos aqueles que investigam sobre a docência e, ainda, entre os que proporcionam a educação nas instituições de Educação Básica e Superior.

\section{Referências}

ADORNO, Theodor Ludwig Wiesengrund. Educaşão e Emancipação. Rio de Janeiro: Paz e Terra, 1995.

AGUIAR, Márcia Angela da Silva; DOURADO, Luiz Fernandes. BNCC e formação de professores: concepções, tensões, atores e estratégias. Retratos da Escola, Brasília, CNTE, v.13, n. 25, p. 33-37, jan./mai. de 2019.

ARANHA, Maria Lúcia de Arruda. Filosofia da educação. São Paulo: Moderna, 1989.

BAZZO, Vera; SCHEIBE, Leda. De volta para o futuro... retrocessos na atual política de formação docente. Retratos da Escola, Brasília, v. 13, n. 27, p. 669-684, set./dez. 2019.

BRASIL. Conselho Nacional de Educação. Resolução CNE/CP n. 02/2015, de $1^{\circ}$ de julho de 2015. Brasília, Diário Oficial [da] República Federativa do Brasil, seção 1, n. 124, p. 8-12, 02 de julho de 2015.

BRASIL. Lei no 13.005, de 25 de junho de 2014. Aprova o Plano Nacional de Educação (PNE) e dá outras providências. Diário Oficial da União [da] República Federativa do Brasil, Brasília, 2014.

CARVALHO, Isis Azevedo da Silva; GONÇALVES, Suzane da Rocha Vieira. Os desafios da implementação das diretrizes curriculares nacionais para a formação de professores no Brasil. Rev. Eletrônica Mestr. Educ. Ambient. e-ISSN 1517-1256, Edição especial XIX Fórum de Estudos: Leituras de Paulo Freire, p. 126-141, junho, 2017. 
CARVALHO, Isis Azevedo da Silva; GONÇALVES, Suzane da Rocha Vieira. Diretrizes Curriculares para a formação de professores: avanços e perspectivas para as licenciaturas. Rev. Educ., Cult. Soc., Sinop/MT/Brasil, v. 8, n. 2, p. 468-480, jul./dez. 2018.

CHAUÍ, Marilena. Convite à filosofia. São Paulo: Ática, 2010.

DOURADO, Luiz Fernandes. Diretrizes Curriculares Nacionais para a Formação Inicial e Continuada dos Profissionais do Magistério da Educação Básica: Concepções e Desafios. Educação \& Sociedade. Campinas, v. 36, n. 131, p. 299-324, abr.-jun., 2015.

FREIRE, Paulo. Pedagogia da autonomia: saberes necessários à prática educativa. 50. ed. Rio de Janeiro: Paz e Terra, 2000.

HOBOLD, Márcia de Souza. A constituição das formas identitárias dos professores/chefes de departamento dos cursos de licenciatura. 2008. Tese (Doutorado) - Programa de Pós-Graduação em Psicologia da Educação, Pontifícia Universidade Católica, São Paulo, 2008.

KUENZER, Acacia Zeneida. As políticas de formação: A constituição da identidade do professor sobrante. Educação \& Sociedade, ano XX, nº 68, dez./1999.

MALLAT, Juliana Domit. Formação Inicial de Professores: a formação pedagógica e a materialização da didática nos cursos de licenciatura da Unicentro. EDUCERE. XIII - Congresso Nacional de Educação. 16473- 16486. ISSN 2176-1396. 2017.

SCHEIBE, Leda. Formação de professores no Brasil: a herança histórica. Revista Retratos da Escola, Brasilia, v. 2, n. 2-3, p. 41-53, jan./dez., 2008. Disponível em: http://www.cnte.org.br/images/stories/2012/revista_retratosdaescola_02_03_2008_formacao_professores.pdf. Acesso em: 28 de agosto de 2017.

SCHWARTZMAN, Simon. A Redescoberta da Cultura. São Paulo: EDUSP, 1997.

WEBER, Max. Ensaios de Sociologia. Rio de Janeiro, Zahar, 1974.

SEVERINO, Antônio Joaquim. Educaşão, sujeito e história. São Paulo, Olho d’água, 2001. 